\title{
5
}

\section{Methodological approaches and considerations in regulatory research}

\author{
Ibolya Losoncz
}

\section{Introduction}

The chapters in this book cover a broad range of regulatory topics through a kaleidoscope of lenses, such as law, sociology, economics, social psychology and theories of regulatory regimes and networks. A notable and shared element of the chapters is the seamless overlaying of two or more lenses to best illuminate the complex connections and interplays between actors, events and mechanisms contributing to regulation. Yet, to date, little work has been published explicitly describing the methodological approaches that might be used to integrate the range of paradigms present in most regulatory research. As a result, those new to the regulatory research field can find themselves in a quagmire of theoretical perspectives brought on by the considerable divergences between, and within, disciplines and their methodological approaches.

The aim of this and the next chapter is to fill this gap by considering two of the many methodological aspects of studying regulation: integrating the objective and subjective concerns informing regulation and accounting for the transnational dimensions of regulation. 
This chapter analyses some of the theoretical considerations we, the researchers, should consider before embarking on our regulatory research project. Included in such an analytical reflection are fundamental questions. What is your underlying logic of seeing the social world and, thus, what theoretical rationale should you adopt for your research project? What methodology, design or chart will you use to navigate your inquiry? What methods, techniques and procedures should you employ to execute your plan? And, importantly, how do the choices that you make influence your findings? What are the things you will not know because your inquiry is limited due to a biased selection of your theoretical rationale, methodology or methods?

The next chapter, by Kathryn Henne, discusses the use of multi-sited fieldwork to address the complex, transnational dimensions of regulation. Regulation is often embedded in world systems and researchers should be attuned to how global, national and transnational systems and discourses inform and affect their studies. Henne proposes field-intensive qualitative methods to analyse the many factors that emerge across structural, systemic and local-level systems. She explains how fieldintensive methods facilitate the gathering of in-depth data to uncover how relationships between the events, social conditions and actors shape regulation, and how participants' perceptions and social context inform the meanings attributed to regulation.

The rest of this chapter is divided into three sections. The first section looks at what regulatory research involves and the implications it has for choices concerning theoretical approach and research design. The second section discusses the principal building blocks of research projects in general, as well as in the context of regulatory research. The chapter concludes with some examples of critical-realist theoretical approaches in regulatory research. 


\section{What does regulatory research involve?}

Regulatory research involves the description and explanation of complex ${ }^{1}$ interplays between structural and systemic conditions and actors and their agency over time and at different levels. Regulating and influencing the behaviour of people and organisations never occur on the basis of a single mechanism (Braithwaite and Drahos 2000). They usually involve a number of leverage points, such as changes in law and norms, changes in networks and protocols or changes in relationships and behaviour. Regulatory controls are enmeshed in webs of legal and social structures, and institutional power, action and ambition. Yet, if institutions want to be successful in influencing people and gaining their cooperation, they need to understand and connect with people's constructions of institutions and institutional actions and ambitions (Braithwaite 2009a, 2009b). At the same time, people's behaviour, or the meanings they attach to events, is worked out within the framework of cultures ${ }^{2}$ and social structures (specific to times, places and groups of people), and regulatory interventions need to consider and reflect the context, values and cultures of the regulatory community (Meidinger 1987).

Some of these elements, such as the power of law and how actors (people and organisations) respond to it (that is, comply, ignore or violate), exist objectively. Yet, actors experience the mechanisms underlying these responses subjectively. The experience is subjective in the sense that it is influenced by the individual, cultural and historical experiences of actors. These subjective experiences have a strong influence on how interactions and relationships with regulatory regimes are constructed. Thus, regulatory research needs to account for both the objective and the subjective.

The relation between the objective and the subjective, and the complex interplays between structural, cultural and agential properties, has important implications for one's methodological approach. Understanding these implications requires a brief, yet systematic, mapping and discussion of the main elements of the social research process - a task taken up in the next section.

1 For distinguishing between simple, complicated and complex problems, see Zimmerman and Glouberman (2002).

2 A set of shared understandings that makes it possible for a group of people to act in concert with each other (Becker 1982). 


\section{The building blocks of the social research process}

There are numerous constructions of the social research process. What I offer here is just one perspective, based largely on Crotty's (1998) framework. Under the perspective I propose, researchers should ask the following three questions:

1. What is my theoretical perspective? That is, in my view, what theoretical rationale would capture effectively the interplay between actors, events and mechanisms?

2. What is my overarching research strategy or methodology?

3. What methods or tools will I use for my data collection?

Answering these questions, in this order, guides researchers in developing a coherent research design and overall consistency. Figure 5.1 is a schematic representation of this process of moving from theoretical rationale to methodology to method, with examples of some $e^{3}$ of the options under each. Next, we turn to a focus on the theoretical rationale with a particular look at critical realism.

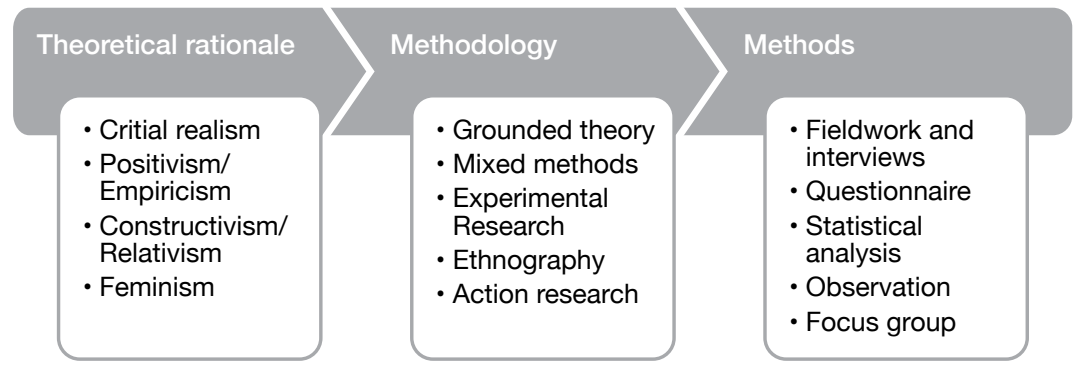

Figure 5.1 The main building blocks of a social research process Source: Adapted from Crotty (1998).

\section{Theoretical rationale}

To adopt a theoretical rationale is to adopt a way of looking at the world and making sense of it. It embodies a certain way of understanding what is (ontology) and a certain way of understanding what it means to know (epistemology) (Crotty 1998). In other words, ontology asks

3 These are just a few examples and not an extensive list of options. 
what is the nature of existence, what constitutes reality and how can we understand existence. Epistemology, on the other hand, asks what constitutes valid knowledge and how can we obtain it. The theoretical rationales most often discussed in the social sciences are those of positivists, also referred to as empiricists, and constructivists, also referred to as relativists.

Positivists hold that there is a single, objective truth or reality and this reality can be captured by finding regularities in observable empirical events. It is the analysis of these patterns that can lead to constructs underlying individual and social lives (Miles et al. 2014). Constructivists, on the other hand, argue that the world and reality are socially constructed and, before we can look for plausible causal relationships between events, we need to understand the experience of these events in terms of people's subjective meanings (Hammersley 2008). Positivist approaches, then, lend themselves to structural-level analysis, while cultural and agential concepts are more adequately analysed from constructivist perspectives. Yet, by simply applying each of those approaches to the appropriate concepts, or level of analysis, we will not be able to adequately capture and account for the relation between the objective and the subjective and the linkages and interactions between social and institutional structures, the agency of actors and regulatory cultures.

Understanding the relationship between structure and agency is a deepseated and persistent problem in social sciences in general (Archer 1995; Bakewell 2010; Carter and New 2004; King 2007). The crux of the challenge is how to acknowledge the importance of both social structures and agency in understanding social action and social change. But why is this such a challenge? To a large extent, the challenge is a consequence of the division, and often dispute, between positivism and constructivism and the inherent inability of either of these approaches to adequately capture and explain the social world on their own.

The main criticism of positivism is ontological flatness (Abbott 2001) that is, equating reality with what is knowable about it through observable events. Many researchers (for example, Danermark et al. 2002; Sawyer 2005; Sayer 2000) also argue that empirical regularities are not sufficient for claims of causal explanation; rather they are pointers to further inquiry to find the generative mechanisms that underlie the regularities. Critiques of constructivism, on the other hand, argue that reality cannot be reduced to experiences and interpretations of reality. Furthermore, by relativising truth, constructivists deny the possibility 
of objective knowledge about the world, and undermine the notion of causal explanation or the ability to adjudicate between different theories of reality (Iosifides 2012). Constructivists also have a tendency to overemphasise the 'discursive processes by which they are constituted and identified by culture members' (Hammersley 2008: 173), whereas the focus should be on what causes phenomena and what effect they produce. Finally, the social actions of actors cannot be restricted to an understanding of meaning-making or agential intentionality as these things are also the subject of structural and cultural context, social relationality and other external conditions (Somers 1998).

Yet mixing positivism and constructivism, or mixing methods resting on competing definitions of knowledge and how it is obtained, without a coherent theoretical rationale for the mix can make things even more complicated. Data collected using different methods cannot simply be added together to produce a unified reality. The analysis of data needs to be integrated and made sense of in relation to each other. Objectivity and subjectivity need to be viewed and treated in 'dialectical unity' (Iosifides 2012:39), despite the fact that they are at different ontological levels. One way out of this ontological quagmire is critical realism. Unlike positivism or structuralism, critical realism has a stratified ontology. Through its stratified levels, it can connect interpretations of reality with objective aspects and patterns to be found in the social world.

\section{Critical realism}

The key feature of critical realism, founded by the British philosopher Roy Bhaskar in the 1970s, is the rejection of 'epistemic fallacy' (Bhaskar 1978: 36), which conflates reality with our knowledge of reality. That is, while critical realism recognises that there exists a reality independent of our representation of it,itacknowledges that our knowledge of reality is subject to a range of social constructions (Danermark et al. 2002; Sayer 2000). It accepts the relativity of all knowledge claims (interpretations of experiences), while critically assessing the validity of related conceptual schemes, theories and interpretations. It does that by distinguishing between three reality domains of empirical, actual and real (Bhaskar 1978; Danermark et al. 2002), as presented in Figure 5.2. The domain of the empirical consists of experiences, concepts and signs, which are known and conceptualised by social agents and researchers. This domain is always theory-impregnated and is always mediated by our theoretical conceptions. The domain of the actual consists of experiences, concepts, signs and events. Unlike experiences that are known through 
conceptualisation (by the social agent or the researcher), events are what happen in the world irrespective of its conceptualisation and knowledge. Finally, the domain of the real includes experiences, concepts, signs, events and generative causal mechanisms - interactions between structures and causal powers exerted by social objects. These causal mechanisms are unobservable at the empirical level, yet they produce observable events, processes and phenomena (Danermark et al. 2002; Sayer 2000).
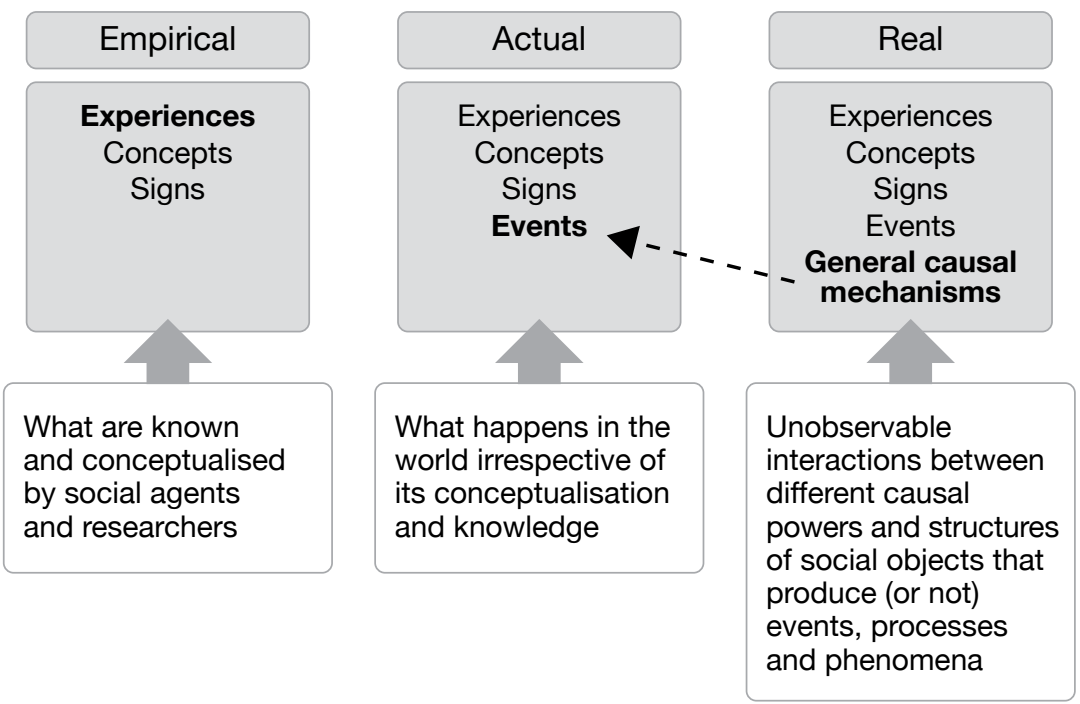

Figure 5.2 The reality domains of critical realism

Sources: Bhaskar (1978); Danermark et al. (2002); Hartwig (2007); Sayer (2000).

The focus of causality in critical realism is not the regularity of observable empirical events (as per positivism), but the generative mechanisms that produce events, processes and phenomena. Causality derives from causal powers exerted by social objects due to their structure. These causal powers are relational and, depending on the interaction between them and other mechanisms, they may be exercised, modified or remain unexercised. It is through this relational phenomenon, labelled social emergence, that critical realism can link structure with agency and bring together individual and social structures, even though they exist on different ontological levels. Instead of conflating them, or reducing each to the other, they are kept analytically distinct with different emergent properties and causal powers, focusing on how their interplay results in social transformation. This 'openness' of the realist paradigm can also account for agency. That is, while people's actions are conditioned, 
they are never determined by structures alone. People can see, choose or be forced to choose alternative actions. In other words, the relationship between causal powers is not only relational, but also contingent (Archer 1995; Danermark et al. 2002; Sayer 2000).

Critical-realist research is theory driven as well as theory generating. Existing theories are used to link concrete phenomena and processes to theoretical and conceptual abstractions to generate new theories. Thus, conceptualisation and conceptual abstractions of phenomena and their emergent properties are critical steps in a critical-realist approach. Although the literature on concept analysis tends to be dominated by the semantic analysis of words (for example, Sartori 1984), researchers who regularly traverse the quantitative and qualitative-for example, Goertz (2006) —would argue that a semantic approach is never adequate by itself, as 'a concept involves a theoretical and empirical analysis' of the phenomenon referred to by the word. A good definition of the phenomenon to be studied is 'relevant for hypotheses, explanations, and causal mechanisms' (Goertz 2006: 4). In short, concepts should focus on what constitutes a phenomenon and which attributes play a key role in causal mechanisms and explanations. This step typically takes researchers to the next building block of inquiry: methodology.

\section{Methodology}

Although the terms methodology and methods are often used as though they mean the same thing, they are different, have a different purpose and should be addressed separately. Methodology is about the underlying logic of research-'our chart to navigate the social world'while methods are 'the tools of our trade' (Castles 2012: 7). The main purpose of methodology is to outline the design and focus of one's research. There are no hard rules on the range of methodologies that can be used by realist researchers, as long as the selected methodology reflects the rationale that critical realism brings to research. Below, I briefly discuss ${ }^{4}$ one example: grounded theory. Multi-sited fieldwork, discussed by Henne in the next chapter, is also compatible with a realist framework.

4 For a detailed and critical assessment of a critical-realist rationale/grounded theory methodology package, refer to Clarke (2003) or Oliver (2012). 


\section{Grounded theory}

Grounded theory is widely used in the social sciences. It is ultimately about uncovering meaning and developing theory grounded in the data. While in the past 50 years, grounded theory has seen numerous modifications from its original form (developed by Glaser and Strauss in 1967), all approaches share its core characteristics: to generate theoretical explanations through a process of concurrent data collection and analysis. This process is performed iteratively through a constant comparative analysis involving moving back and forth through increasingly focused data. The researcher gradually links initial codes into progressively abstracted higher-level categories and conceptual themes (Charmaz 2006; Glaser 1992; Glaser and Strauss 1967).

The power of grounded theory and its important contribution to the critical-realist rationale is its analytical process that leads to a theorising of how actions, meanings and social structures are constructed. It requires researchers to move beyond describing data to think analytically about the data by applying pre-existing theoretical knowledge of concepts. Yet, extant theories have to 'earn' their way into the analysis based on extensive inductive analytical work, instead of stamping their preconceived ideas on the data (Charmaz 2006). We can see, then, how critical-realist research can draw considerably on grounded theory to support its iterative process of abstraction. The one point of difference is the position held by the critical realist that data produced from participant narratives are not a sufficient basis alone for theory. Analysis (that is, coding) needs to connect categories and abstraction of data to their emergent properties (Bakewell 2010; Pratt 1995).

\section{Methods}

The final step in developing a research plan is selecting methods, or research tools, to execute the research plan. Critical realism does not claim to develop new methods; it simply reorients and links existing theoretical paradigms (Danermark et al. 2002). Thus, existing quantitative and qualitative research tools used in those paradigms can also be used and combined in critical-realist research, provided the researcher is aware of the functions of these methods in the criticalrealist framework. To explore these functions, this section will describe the four main forms of inferences typically used in critical-realist 
research: deduction, induction, abduction and retroduction. We can view these complementary techniques as different thought operations of moving from one thing to something else.

Deduction and induction are well known and frequently used in the social sciences. In a deductive approach, knowledge of individual phenomena is derived from universal laws by the use of formal logic and set inference rules. Inductive reasoning works in the opposite way: inferences about larger populations are drawn from individual observations. The main limitation of these two techniques is that they give no guidance as to how, from something observable, we can reach knowledge of underlying structures and mechanisms. Thus, to identify causal generative mechanisms, unobservable at the empirical level, critical realists often need to go beyond induction and deduction and use abductive and retroductive reasoning.

Abduction and retroduction are seldom discussed in the literature on method despite their important contribution. Abduction involves taking a known phenomenon and recontextualising it by using existing general theories. It is reinterpreting something as something else, understanding it within a different frame of context. This reinterpretation then provides new meaning, new insight and possibly a more developed or deeper conception. Social scientists rarely discover new events; instead, they discover 'connections and relations, not directly observable, by which we can understand and explain already known occurrences in a novel way' (Danermark et al. 2002: 91). A wellknown example of recontextualisation ${ }^{5}$ is Giddens's interpretation of anorexia as a manifestation of reflexive identity-a characteristic of postmodern society. In his theorisation, a 'tightly controlled body is an emblem of a safe existence' in a plural, ambiguous social environment (Giddens 1991: 107).

If abduction is a theoretical redescription then the focus of retroduction is identifying what is fundamentally constitutive for the structures and relations highlighted in this theoretical redescription. That is, what are the basic characteristics of the general structures from which we interpret and recontextualise particular actions and events? Retroduction requires the researcher to go beyond empirically observable events

5 Other well-known examples of abduction include Marx's recontextualisation of the history of man, Durkheim's recontextualisation of suicide, Darwin's redescription of the evolution of species and Freud's interpretation of people's dreams. 
and characteristics by asking questions about the more fundamental, transfactual conditions for such events. Such questions are constantly asked by philosophers, but can also be asked in relation to norms, rules or for structuring particular actions. Specific strategies to produce retroductive questions and inferences include: counterfactual thinking, social experiments, studies of pathological cases, studies of extreme cases and comparative case studies (Danermark et al. 2002).

All four types of inference are fundamental tools in regulatory research. Typically, we have to use more than one of these complementary inferences in a single regulatory research inquiry, and there is often a need to mix methods. As signalled earlier, quantitative approaches are well suited for describing the macrosocial changes of a given regulatory context, while qualitative approaches are ideal to uncover regulatory cultures and individual and community-level responses and social actions (see Henne, Chapter 6, this volume). Recent developments in vocabulary, taxonomy, process description and systematic integrative procedures ${ }^{6}$ have provided mixed-methods research with more sophistication and refinement. Despite these developments, most mixed-methods research tends to show limited integration of the range of data and methods used, partly because of the limited ability of existing theoretical rationales to support both qualitative and quantitative methods. But, as we saw in the section on theoretical rationale, critical realism has the capacity to treat qualitative and quantitative methods as part of a dialectical unity.

\section{Examples of a critical-realist approach in regulatory research}

There are plentiful examples in the social sciences of adopting the theoretical and methodological premises of critical realism, from migration research (George 2000; Walby 2009) to research exploring the dynamic relationship between globalisation and inequalities (Carter 2000). An example of a critical-realist approach within the regulatory field is research by Losoncz (2015) demonstrating the effect of government policies and programs on the resettlement styles and strategies of migrants, and their impact on integration outcomes.

6 For more information on the different types of mixed-methods design and their applications, refer to one of the many textbooks on mixed-methods research (for example, Bergman 2008; Creswell and Plano Clark 2010; Teddlie and Tashakkori 2008; Thomas 2003). 
Despite robust claims that integration outcomes are influenced by not only individual characteristics, resources and strategies adopted by migrants, but also acculturation attitudes and public policies and programs of the receiving society, our understanding of these processes and facilitators is insufficient. An important step towards a better understanding of integration is to focus on the conceptualisation of these processes, their causal properties and the generative causal mechanisms through which they influence integration outcomes.

The research adopted a general theory of goals and means put forward by Merton (1968) to demonstrate that current Australian resettlement policies are dominated by a strong emphasis on migrants adopting their new country's cultural goals (such as economic participation and tests of citizenship), without a corresponding emphasis on ensuring that there are effective means for migrant groups to achieve these goals. Resettled migrants are expected, after a brief transition period, to use the standard modes of means-ones that have been designed for the mainstream population and delivered by mainstream institutions. The assumption is that existing mechanisms and protocols (such as impersonality, equity, uniformity and universalism, codes of conduct, the merit-based recruitment system) developed to ensure that institutions provide equal access to all members of Australian society will also ensure equal rights for resettled humanitarian and other migrant groups. Losoncz (2015) argued that these processes do not account for the disadvantage of migrant groups and fail to provide equitable paths to shared goals and ambitions. Instead, these mechanisms favour those already socialised to the functioning and operation of these institutions. Thus, mechanisms of fairness become a charade, blocking pathways to social and economic security among migrants. Some migrant groups responded by retreating from government and social institutions and from the broader Australian community. Such social distancing from institutions and communities can have long-term detrimental impacts on both the migrant and the broader society. It can lead to entrenched resentment and systemic problems, including anomie and deviance in structurally excluded and stigmatised communities (Merton 1968).

For this research, critical realism provided an ideal approach for acknowledging the multilayered social reality of resettlement and for adequately framing an interdisciplinary understanding of resettlement concepts and processes. The use of grounded theory methodology within a critical-realist approach provided a robust research design to integrate 
participants' narratives with attributes of government bureaucracies and social structures of Australian society. That is, grounded theory directed the researcher to uncover evidence and meanings among participants, while critical-realist inquiry drove the researcher to go beyond describing meanings to examining and analysing the structures that generate them. Finally, mixed methods accommodated the integration of multiple data sources and analysis techniques. While interviews were the primary source of data, this information was augmented through ethnographic fieldwork. The subjective experience of social and economic integration outcomes reported by participants was compared with objective measures available from Australian population census data. This use of multiple data sources and methods brought layered, yet convergent meanings (Lincoln and Guba 1985) to the research and has contributed significantly to the trustworthiness (Maxwell 1992) of the findings claimed by the researcher.

Although to date there are few examples of regulatory research explicitly inspired by realist principles, there are plentiful examples of regulatory research that adopts the theoretical and methodological premises of critical realism. Valerie Braithwaite's theory of tax defiance has connected psychological processes of people's fears, hopes and expectations with public policy and the operation of authorities administering the policy. She has used sophisticated structural equation modelling techniques to test her theoretical models predicting resistance and dismissiveness (Braithwaite 2009a). Another example is John Braithwaite's (1989) reintegrative shaming theory (RST). The theory has been highly influential in providing a rationale for restorative justice conferencing in Australia and internationally. The basic idea of the RST is that societies, communities and families among whom shame is communicated effectively and reintegratively are less likely to experience crime than places where shame is communicated in a stigmatising way or not communicated at all. A key concept in the theory is the distinction made between stigmatic shaming and reintegrative shaming. The theory argues that reintegrative shaming reduces crime, while stigmatic shaming increases it (Braithwaite 1989).

In his theory, Braithwaite drew on aspects of Hirschi's control and social bond theories, Sutherland's differential association theory and Becker's labelling theory (Makkai and Braithwaite 1994). According to the labelling perspective on delinquency, disapproving actions or reactions by other people affect the negative beliefs and feelings individuals develop 
about themselves (Taylor et al. 1973). But, critics of labelling theory maintained that any such statement needs to be refined by identifying alternative outcomes of labelling and specifying the conditions under which each is likely to occur (Grimes and Turk 1978). Braithwaite's theory refined and clarified labelling theory. It also provided a deeper conception of shaming by partitioning stigmatising shaming from reintegrative shaming. By exploring and identifying the variety of qualities and structures involved in shaming, the RST demonstrates how shaming can be contingently damaging or beneficial. That is, while labelling offenders may make them view themselves as outcasts and adopt a deviant identity, there is an alternative outcome, as long as it is the act that is being labelled and not the person. Following the labelling of the wrongful act and holding offenders responsible for their behaviour, offenders are forgiven and accepted back into their family and community. Other important conditions facilitating reintegration include a communitarian society and a strong family system characterised by a sense of interdependency.

The development of the theory started out with observational data of encounters between regulatory inspectors and firms in a nursing home context, followed by various quantitative methods to empirically test initial propositions. Methods included principal component analysis to measure the concept of reintegration and multiple regression analysis to estimate the impact of reintegrative shaming on compliance (Makkai and Braithwaite 1994). The development of the theory has seen a number of empirical tests and validations. To explore the dimensionality of reintegration and stigmatisation, Harris (2001) used explanatory factor analyses followed by confirmatory analysis in a restorative justice context, while the relationship between shaming and shame was tested using hierarchical regression analysis.

The RST is one of the compelling examples of how the integration of existing theories to analyse social reality can generate a new and highly influential theory of social transformation. The RST is also an example of theoretical redescription of existing constructs (abduction) and identifying the prerequisites or conditions under which those new constructs occur (retroduction). 


\section{Conclusion}

Regulatory research is an interdisciplinary field. Yet, without a theoretical approach that can connect the theoretical foundations and assumptions of disciplines, one's research could become flat, fragmented, unconnected or confused. This chapter has considered critical realism as a methodological approach to provide a framework for interdisciplinarity. It has explained how critical realism can deal with the analytically distinct structural, cultural and agential elements of the regulatory realm to capture their interplay and the causal mechanisms involved in producing social change or reproduction. Critical realism can be especially useful for those less experienced in regulatory research, because of its propensity to lead researchers from simply uncovering and describing phenomena to examining and analysing the powers generating them and developing theories of their production. This is important as, without the theoretical explanations of these generative causal mechanisms, one's research is in danger of establishing little more than banal descriptions.

\section{Further reading}

Cruickshank, J 2003. Realism and Sociology: Anti-foundationalism, Ontology and Social Research. Abingdon, UK: Routledge. doi. org/10.4324/9780203163948.

Harrits, GS 2011. 'More than method? A discussion of paradigm differences within mixed methods research', Journal of Mixed Methods Research 5(2): 150-66. doi.org/10.1177/1558689811402506.

\section{References}

Abbott, A 2001. Time Matters: On Theory and Method. Chicago: University of Chicago Press.

Archer, MS 1995. Realist Social Theory: The Morphogenetic Approach. Cambridge: Cambridge University Press. doi.org/10.1017/ CBO9780511557675. 
Bakewell, O 2010. 'Some reflections on structure and agency in migration theory', Journal of Ethnic and Migration Studies 36(10): 1689-708. doi.org/10.1080/1369183X.2010.489382.

Becker, HS 1982. 'Culture: A sociological view', The Yale Review 71: 513-27.

Bergman, MM 2008. Mixed Methods Research. Thousand Oaks, CA: Sage. doi.org/10.4135/9780857024329.

Bhaskar, R 1978. A Realist Theory of Science. Brighton, UK: Harvester Press.

Braithwaite, J 1989. Crime, Shame and Reintegration. Cambridge: Cambridge University Press. doi.org/10.1017/CBO9780511804618.

Braithwaite, J and Drahos, P 2000. Global Business Regulation. Cambridge: Cambridge University Press.

Braithwaite, J and Makkai, T 1994. 'Trust and compliance', Policing and Society 4(1): 1-12. doi.org/10.1080/10439463.1994.9964679.

Braithwaite, V 2009a. Defiance in Taxation and Governance: Resisting and Dismissing Authority in a Democracy. Cheltenham, UK: Edward Elgar. doi.org/10.4337/9781848449077.

Braithwaite, V 2009b. 'Tax evasion', in M Tonry (ed.), Handbook on Crime and Public Policy. Oxford: Oxford University Press, pp. 381-405.

Carter, B 2000. Realism and Racism: Concepts of Race in Sociological Research. London: Routledge.

Carter, B and New, C 2004. Making Realism Work: Realist Social Theory and Empirical Resarch. Abingdon, UK: Routledge.

Castles, S 2012. 'Understanding the relationship between methodology and methods', in C Vargas-Silva (ed.), Handbook of Research Methods in Migration. Cheltenham, UK: Edward Elgar, pp. 15-36. doi.org/10 .4337/9781781005231.00007.

Charmaz, K 2006. Constructing Grounded Theory: A Practical Guide through Qualitative Analysis. Thousand Oaks, CA: Sage. 
Clarke, A 2003. 'Situational analyses: Grounded theory mapping after the postmodern turn', Symbolic Interaction 26(4): 553-76. doi. org/10.1525/si.2003.26.4.553.

Creswell, J and Plano Clark, V 2010. Designing and Conducting Mixed Methods Research, 2nd edn. Thousand Oaks, CA: Sage.

Crotty, M 1998. Foundations of Social Research: Meaning and Perspective in the Research Process. Sydney: Allen \& Unwin.

Danermark, B, Ekström, M, Jakobsen, L and Karlsson, JC 2002. Explaining Society: Critical Realism in the Social Sciences. Abingdon, UK: Routledge.

George, S 2000. “Dirty nurses" and "men who play": Gender and class in transnational migration', in M Burawoy, JA Blum, S George, Z Gille and M Thayer (eds), Global Ethnography: Forces, Connections, and Imaginations in a Postmodern World. London: University of California Press, pp. 144-74.

Giddens, A 1991. Modernity and Self-identity: Self and Society in the Late Modern Age. Cambridge: Polity Press.

Glaser, B 1992. Basics of Grounded Theory Analysis. Mill Valley, CA: The Sociology Press.

Glaser, B and Strauss, A 1967. The Discovery of Grounded Theory. New York: Aldine Publishing.

Goertz, G (ed.) 2006. Social Science Concepts: A User's Guide. Princeton, NJ: Princeton University Press.

Grimes, RM and Turk, AT 1978. 'Labeling in context: Conflict, power, and self-definition', in MD Krohn and R Akers (eds), Crime, Law and Sanctions: Theoretical Perspectives. Beverly Hills, CA: Sage, pp. 39-58.

Hammersley, M 2008. Questioning Qualitative Inquiry: Critical Essays. London: Sage. doi.org/10.4135/9780857024565.

Harris, N 2001. 'Shaming and shame: Regulating drink-driving', in N Ahmed, J Harris, J Braithwaite and V Braithwaite (eds), Shame Management through Reintegration. Cambridge: Cambridge University Press, pp. 73-205. 
Hartwig, M (ed.) 2007. Dictionary of Critical Realism. Abingdon, UK: Routledge.

Iosifides, T 2012. 'Migration research between positivistic scientism and relativism: A critical realist way out', in C Vargas-Silva (ed.), Handbook of Research Methods in Migration. Cheltenham, UK: Edward Elgar, pp. 26-49. doi.org/10.4337/9781781005231.00008.

King, A 2007. 'Why I am not an individualist', Journal of Theory of Social Behaviour 37(2): 211-19. doi.org/10.1111/j.14685914.2007.00334.x.

Lincoln, YS and Guba, EG 1985. Naturalist Inquiry. Newbury Park, CA: Sage.

Losoncz, I 2015. 'Goals without means: A Mertonian critique of Australia's resettlement policy for South Sudanese refugees', Journal of Refugee Studies, 5 December. doi.org/10.1093/jrs/fev017.

Makkai, T and Braithwaite, J 1994. 'Reintegrative shaming and compliance with regulatory standards', Criminology 32: 361-85. doi. org/10.1111/j.1745-9125.1994.tb01158.x.

Maxwell, JA 1992. 'Understanding and validity in qualitative research', Harvard Educational Review 62(3): 279-300. doi.org/10.17763/ haer.62.3.8323320856251826.

Meidinger, E 1987. 'Regulatory culture: A theoretical outline', Law Eo Policy 9(4): 355-86. doi.org/10.1111/j.1467-9930.1987. tb00416.x.

Merton, RK 1968. Social Theory and Social Structure. New York: Free Press.

Miles, MB, Huberman, MA and Saldana, J 2014. Qualitative Data Analysis: A Methods Sourcebook. Thousand Oaks, CA: Sage.

Oliver, C 2012. 'Critical realist grounded theory: A new approach for social work research', British Journal of Social Work 42(2): 371-87. doi. org/10.1093/bjsw/bcr064.

Pratt, AC 1995. 'Putting critical realism to work: The practical implications for geographical research', Progress in Human Geography 19(1): 61-74. doi.org/10.1177/030913259501900104. 
Sartori, G 1984. 'Guidelines for concept analysis', in G Sartori (ed.), Social Science Concepts: A Systemic Analysis. Los Angeles: Sage, pp. 15-48.

Sawyer, KR 2005. Social Emergence: Societies as Complex Systems. Cambridge: Cambridge University Press. doi.org/10.1017/ CBO9780511734892.

Sayer, A 2000. Realism and Social Science. London: Sage. doi. org/10.4135/9781446218730.

Somers, MR 1998. 'We're no angels: Realism, rational choice, and rationality in social science', American Journal of Sociology 104(3): 722-84. doi.org/10.1086/210085.

Taylor, I, Walton, $\mathrm{P}$ and Young, J 1973. The New Criminology: For a Social Theory of Deviance. London: Routledge \& Kegan Paul. doi.org/10.4324/9780203405284.

Teddlie, C and Tashakkori, A 2008. Foundations of Mixed Methods Research. Thousand Oaks, CA: Sage.

Thomas, RM 2003. Blending Qualitative and Quantitative Research Methods in Theses and Dissertations. Thousand Oaks, CA: Corwin Press.

Walby, S 2009. Globalization and Inequalities: Complexity and Contested Modernity. London: Sage.

Zimmerman, B and Glouberman, S 2002. Complicated and complex systems: What would successful reform of Medicare look like?, Discussion Paper No. 8, Commission on the Future of Health Care in Canada, Government of Canada Publications, Ottawa. 
This text is taken from Regulatory Theory: Foundations and applications, edited by Peter Drahos, published 2017 by ANU Press, The Australian National University, Canberra, Australia. 